\title{
Effectiveness of Household Emergency Plans in Violent Tornadoes
}

\author{
Zhen Cong, PhD (1); Daan Liang, PhD, PE; Jianjun Luo, PhD
}

\section{ABSTRACT}

Objective: This study examined factors that were associated with the effectiveness of pre-existing household emergency plans during the 2011 EF5 Joplin and EF4 Tuscaloosa tornadoes. We focused on whether discussing with family members helped increase the plan's effectiveness.

Methods: A telephone survey based on random sampling was conducted in 2012 with 1006 respondents in both cities. Each city experienced huge losses, injuries, and casualties. The working sample included 494 respondents who had a household emergency plan in place before these tornadoes.

Results: Multinomial logistic regression showed that discussing with family members increased the helpfulness of the plan in Joplin, where people had not experienced tornadoes frequently and were less prepared for tornadoes relative to residents in Tuscaloosa.

Conclusions: This study provides empirical evidence on the importance of encouraging family involvement when making household emergency plans, especially in places that are less prepared for disasters than those that are better prepared.

Key Words: disaster preparedness, household emergency plan, tornado, vulnerability

$\mathrm{T}$ ornado warnings are usually issued minutes before the storm touchdown, giving little time for discussing and carefully weighing different options. ${ }^{1}$ Studies have shown that having a household emergency plan (HEP) helped individuals take appropriate protective action in tornadoes and thus reduce casualties and save lives. ${ }^{2}$ Although the importance of having an HEP is acknowledged and family involvement is encouraged, few studies have empirically examined the helpfulness of those plans and the importance of family involvement when disasters happen.

\section{METHODS}

A random digit-dialing telephone survey was conducted with 1006 respondents in October 2012, a little more than 1 year after the EF-5 tornado in Joplin, Missouri, which caused over 160 fatalities and 1000 injuries, and an EF-4 in Tuscaloosa, Alabama, which caused over 60 fatalities and 1500 injuries $^{3} ; 538$ respondents had an HEP before the tornadoes and 522 reported the helpfulness of their plans. Listwise deletion of missing values in other variables further reduced the sample size to 494 respondents.

Respondents were asked about whether they had an emergency plan in place before the tornadoes and, if yes, they were further asked: How much did the plan help you for this tornado? They were also asked: Have you ever discussed the plan with your family before the tornado $\left(0=N_{o}, 1=Y e s\right)$ ?
Multinomial logistic regression was used to examine relationships between family discussions and whether the plan provided a lot of help, some help, versus no help at all (reference). Demographic information controlled included age, gender, education, marital status, and race. Functional limitations in walking, running, vision, and hearing were also controlled.

\section{RESULTS}

Results showed that discussing with family members significantly increased the odds ratio (OR) $(\mathrm{OR}=3.14, P<0.05)$ of reporting an HEP having provided a lot of help versus no help in Joplin. Discussing with family members did not affect the helpfulness of an HEP in Tuscaloosa.

\section{DISCUSSION}

The difference between Joplin and Tuscaloosa concerning the effect of discussion among family members might be related to the differences in these 2 cities with respect to their preparedness for tornadoes. Tuscaloosa residents experienced significant tornadoes several times over the past several decades, and 1 happened just 1 week before the violent tornado. ${ }^{3}$ In contrast, Joplin residents experienced much fewer tornado events. Because of that, Tuscaloosa communities might generally be more prepared for tornadoes and better understand what to expect and what to do when tornadoes happen. ${ }^{4}$ Thus, even without discussing with 
family members, their plans may be well-developed and helpful. Overall, we suspect that a family discussion of an HEP is more important in places that are less prepared for disasters than in those that are better prepared.

\section{CONCLUSION}

This study only includes whether the plan was discussed with family members and does not have other information about family mechanisms. In the future, a detailed examination about family involvement in the plan-making process will contribute to important knowledge on reducing the casualties and losses caused by disasters. In addition, future research should address how different components of an HEP are associated with its effectiveness in disasters.

\section{About the Authors}

School of Social Work, The University of Texas at Arlington, Arlington, TX (Dr Cong); Department of Civil, Construction and Environmental Engineering, The University of Alabama, Tuscaloosa, AL (Dr Liang); and Catastrophe Modeling and Risk Assessment, AIR Worldwide, Boston, MA (Dr Luo).
Correspondence and reprint requests to Zhen Cong, The University of Texas at Arlington, School of Social Work, 211 S. Cooper St., Arlington, TX 76019 (e-mail: zhen.cong@uta.edu)

\section{Financial Support}

This material is based upon work supported in part by the National Science Foundation under grants CMMI 1839516 and CMMI 1400224

\section{Conflict of Interest Statement}

The authors have no conflicts of interest to declare.

\section{REFERENCES}

1. Brooks HE, Correia J Jr. Long-term performance metrics for National Weather Service tornado warnings. Weather Forecast. 2018;33(6):15011511.

2. Cong Z, Liang D, Luo J. Family emergency preparedness plans in severe tornadoes. Am J Prev Med. 2014;46(1):89-93.

3. National Oceanic and Atmospheric Administration's National Climatic Data Center. Storm events database. Published 2016. https://www.ncdc. noaa.gov/stormevents/. Accessed March 1, 2018.

4. National Weather Service. Service assessment - the historic tornadoes of April 2011. Published 2011. http://www.nws.noaa.gov/om/assessments/ pdfs/historic_tornadoes.pdf. Accessed December 20, 2016. 